\title{
Occupational Injuries in Automobile Repair Workers
}

\author{
Heer VYAS ${ }^{1}$, Subir DAS ${ }^{1}$ and Shashank MEHTA ${ }^{1}$ \\ ${ }^{1}$ National Institute of Design, Paldi, Ahmedabad-380007, India
}

Received February 23, 2011 and accepted July 7, 2011

Published online in J-STAGE August 9, 2011

\begin{abstract}
Mechanics are exposed to varied work stressors such as hot noisy environments, strenuous postures, improperly designed tools and machinery and poor psycho-social environments which may exert an influence on their health and safety. The study aimed to examine the occupational injury patterns and identify work stressors associated with injury amongst automobile mechanics. A descriptive ergonomic checklist and questionnaire on general health and psycho-social issues were administered to male workers $(\mathrm{N}=153)$. The relative risk factors and correlation statistics were used to identify the work stressors associated with occupational injury. $63 \%$ of the workers reported injuries. Cuts were the chief injuries being reported. Poor work environment, machinery and tool characteristics, suffering from poor health and psycho-social stressors were associated with injury occurrence amongst automobile repair workers.
\end{abstract}

Key words: Automobile repair workers, Work stressors, Occupational injury, Pain, Psycho-social stress

\section{Introduction}

In India, workers employed as automobile garage workers are low-wage workers. Automobile repair workers are characterized by a predominantly male workforce. They perform tasks such as spray painting, repairing, cleaning, welding, servicing and general work (such as washing, test driving), etc.

Work stressors present in this occupation are exposures to uv and thermal radiation, hot noisy environments, presence of dust, fumes, oils, grease and other chemicals, strenuous work postures, improperly designed tools and machinery and work in poor psycho-social environments ${ }^{1-3)}$. Mechanics have higher rates of occupational health hazards compared to workers in other occupations ${ }^{4,5)}$. There is evidence from research in the Netherlands, United Arab Emirates, Africa and Bangkok which suggests that automobile repair workers suffer from varied nature of health complaints such as injury, pain, respiratory symptoms, cancers, eye related prob-

*To whom correspondence should be addressed. E-mail: heerpvyas@gmail.com; heer.v@nid.edu lems and skin problems ${ }^{7,8)}$. Automobile repair workers during a typical day adopt different working postures, are exposed to poor psychosocial environments and are engaged in repetitive work which might impose a stress and further lead to injury causation ${ }^{8,9)}$. There are a few occupational health studies which have focused on Indian garage workers in relation to respiratory health complaints ${ }^{10)}$ but there is limited evidence in relation to injury occurrence in this workgroup.

Studies have reported that the occurrence of occupational injuries is attributed to multiple factors related to worker's characteristics, their health and work stressors. Worker characteristics such as gender, age, duration of employment, lifestyle, body mass index and literacy level have been known to influence injury occurrence ${ }^{11-13)}$. Workers suffering from disease or psychosomatic disorders, health complaints and musculoskeletal discomforts have been reported at a higher injury risk ${ }^{14)}$. Work stressors such as elongated work schedules, overcrowded work stations, noisy environment, improperly designed hand tools and machinery characteristics have been known to result in occupational injury occurrence $\left.{ }^{15}, 16\right)$. Psycho-social work char- 
acteristics and stress symptoms such as high workload, fatigue, high cognitive demands, anxiety and low job satisfaction have been reported to significantly increase risk of occupational injury ${ }^{5,17)}$. Additional research is needed to understand the prevalence of occupational injury and identify the factors associated with it among automobile repair workers.

The aim of this study was to estimate the prevalence of occupational injuries and to examine the factors associated with occupational injuries amongst automobile repair workers in India. The study attempted to take into account factors such as worker characteristics, their health conditions and stress symptoms and work stressors in relation to occurrence of occupational injury.

\section{Method}

\section{Participants}

A study was conducted by introducing interviewer administered questionnaires in the Ahmedabad city, situated at western province of India in the months of July, 2010 to December, 2010. There are a large number of small scale enterprises which are engaged in the repairing, servicing and maintenance of automobiles in this area. We approached about 45 different small scale units and about 35 units agreed to participate in the study (participation rate 78\%). 153 male mechanics from thirty five different businesses volunteered for this study. The study was conducted in compliance with the National Institute of Design's ethical guidelines. The Institutional Ethical Committee's clearance was obtained to conduct the study and informed consent was obtained from each participant for the study.

\section{Survey}

Occupational injury

The question assessing occupational injury was "Have you ever being injured during work including minor scratches and cuts, in the 1 year period?" The possible response was either yes or no. Workers were further asked to mention their injury type (e.g. cuts, burns, scratch, piercing, etc.) and site of the injury. A one year period was chosen to identify the prevalence of occupational injury and the most recent injury suffered by repair workers was noted down by the investigators.

Health, pain and stress symptoms

A general health questionnaire including work related hazards was introduced among the volunteers. Workers who demonstrated either eye related, respiratory or skin related problems were considered as belonging to poor health status. The prevalence patterns of muscle-skeletal discomforts among the workers in the last twelve months were recorded with a questionnaire on musculoskeletal pain and discomforts ${ }^{18)}$.

In addition, stress dimensions such as the somatic and cognitive anxiety ${ }^{20)}$ (physiological and psychological state of anxiety), the extent of social and domestic disruption ${ }^{21)}$, (impairment in domestic and social activities), and the Eysenck Personality Inventory for neuroticism and extroversion" ("a mental state of depression, anxiety, anger, phobias attitude, etc. that orient a person towards the external objective world") ${ }^{22}$ ) and chronic fatigue (characterized by exhaustion, impaired sleep, lethargic and feeling of drained) were assessed ${ }^{23)}$.

\section{Work analysis}

Work analysis, such as job characteristics, physical and psychosocial stresses of works, constraints of workplace and tools, hazards of physical environment etc as presented in Table 1 was carried out by multimethod ergonomic checklist ${ }^{24)}$. Workers were asked for their response about their perception of the work aspect to be strenuous and their response was noted down by the investigators. The checklist entries were responded by a single digit score, on a common five point scale ranging from strong disagreement (1) to strong agreement (5) and where a low score indicated the perception of absence of a problem. The relative loading of scores for each section of the checkpoints was arrived at from the ratio of the summated score value to that of maximum cumulative scores possible under that section. The values greater than mid value of maximum possible score were considered as the positive indicator of the stressors. In other words, for each of the work stressors, the relative loadings would range within 0 to 1 and the loading of each aspect of work equal to or more than 0.5 was considered as a stressor.

\section{Statistical analysis}

Data analysis was performed using SPSS statistical software, version 16.0. The descriptive statistics, including prevalence percentage and the odd ratios of the test measures were obtained with reference to work groups, physical characteristics, physiological and psycho-social stressors. The normality of data was checked by Kolmogorov-Smirnov Test with Lilliefor's correction and the distribution of the data for most variables was found to be normal with $p>0.05$ for all the variables. The relationship of the work stressors, pain, health symptoms and psycho-social stressors and stress symptoms to injury was examined by relative risk estimates. The reliability co-efficient for internal consistencies (Cronbach's alpha) of the ergonomics checklists were examined and the alpha values (0.84) indicated adequate reliability. Multivariate analysis was done 
Table 1. Details of ergonomics checklist

\begin{tabular}{|c|c|}
\hline Work aspects & Details \\
\hline Job specialization & Specific job, production volume, quality of work and multiple task \\
\hline Skill requirement & Training, knowledge, skill required for job, frequent mistakes at work, job rotation and machine paced work \\
\hline Physical work & Target oriented pace, repetitive movements, muscular exertion and working position \\
\hline MMH & Load handling mode, load weight, distance, height, etc. \\
\hline Task situation & Material package, handle position, unsafe practices and mechanical aids \\
\hline Workplace design & Work distance away from normal reach, non-adjustable work desk height, poor clearance space, presence of obstacles \\
\hline Seating arrangement & Mismatched dimensions, poor adjustability, absence of vibration damping and absence of hold-support \\
\hline Auxiliary support & $\begin{array}{l}\text { Storage space, restricted passage, design mismatches of staircase, awkward positioning of limbs for hand-foot hold, poor } \\
\text { supports }\end{array}$ \\
\hline Work posture & $\begin{array}{l}\text { Arm stretch, wrist extension, neck/shoulder angle, bent and twisted, hips and legs not supported, one sided body movement } \\
\text { etc }\end{array}$ \\
\hline Noise & Noise at work area, absence of sound isolation and emergence measures \\
\hline Climate & Temperature, humidity, ventilation device etc. of the workplace \\
\hline Lighting & Illumination intensity, presence of shadows etc. \\
\hline Dust & Presence of dust, poor ventilation, absence of protective measures \\
\hline Vibration & $\begin{array}{l}\text { Transmission of vibration by feet, hand-arm and seat, prolong and continuous exposures and possibility to eliminate or iso- } \\
\text { late }\end{array}$ \\
\hline Work schedule & $\begin{array}{l}\text { Working in nights and overtime, uneven distribution of work tasks incorporation of work rest and working at a predeter- } \\
\text { mined pace limit }\end{array}$ \\
\hline Machinery control & $\begin{array}{l}\text { Awkward positioning, mismatched dimensions with body parts, force, speed and precision required in operation, and } \\
\text { unpleasant feelings while operation }\end{array}$ \\
\hline $\begin{array}{l}\text { Machinery } \\
\text { characteristic }\end{array}$ & $\begin{array}{l}\text { Instability, maintenance, speed, handle operation, guarding, warning signal, absence of vibration damping, high noise level } \\
\text { and poor visibility of machine }\end{array}$ \\
\hline Tools & Using with alternate hands, weight, handle form and position, sharp edged \\
\hline Machinery safety & $\begin{array}{l}\text { Removal and fastening of accessories, poor positioning, contact with body parts, difficult to inspect and lack of instruction } \\
\text { for safe operation }\end{array}$ \\
\hline Job autonomy & Time schedules, absence of assistance and insufficient people at assistance of work, rigid methods of work \\
\hline Job feedback & Role in decision making, increased attention demand for machine operation, assessment by others job performance \\
\hline Task clarity & Unambiguous goal, job restrictiveness, work machine conflict, restricted stimulation, boredom, poor scope \\
\hline Mental overload & $\begin{array}{l}\text { Information load, high information handling, high workload, repetitive act, superficial attention, multiple choice and simple } \\
\text { motor act }\end{array}$ \\
\hline Training & Advancement to higher levels, lack of opportunities, poor training and incentives \\
\hline
\end{tabular}

using binary logistic regression model with backward elimination method in order to understand the effects of work stressors and worker characteristics on the occurrence of injury. In the regression model, variables like work aspects variables and psycho-social stressors and symptoms were fed as continuous variables, whereas variables like age $>35$, experience $<10 \mathrm{yr}$, working for more than $6 \mathrm{~h}$, being married, being literate, suffering from pain and having health related complaints were applied as categorical covariates. All the variables were applied simultaneously in the logistic regression model (Backward LR) in order to derive the effect of every individual variable on injury occurrence.

\section{Results}

\section{Job description of automobile repair workers}

Participating mechanics specialized in a particular vehicle type and were known as bus, truck, car or motorcycle mechanics. Mechanics worked either in service stations, small workshops or open environment. They were exposed to noisy and hot environments. Most of the repair shops had a group consisting of 5-6 workers. The workers performed activities such as repairing, welding, spray painting, service and maintenance, washing etc. as shown in Fig. 1.

Spray painters washed and treated surfaces with water or other cleaning media. They then selected premixed paint or mixed paint components and applied coats of paint using brushes, spray guns and rollers. Specifically they performed tasks such as applying, blowing, brushing, calculating, cleaning, sanding, scraping, screwing and unscrewing, touching up etc. They serviced and overhauled automobiles and associated motor vehicle; examined vehicles to ascertain the nature, extent and location of defects; planned work; dismantled engines transmissions, differentials or other parts requiring attention; repaired or replaced parts such as rods, gears, 

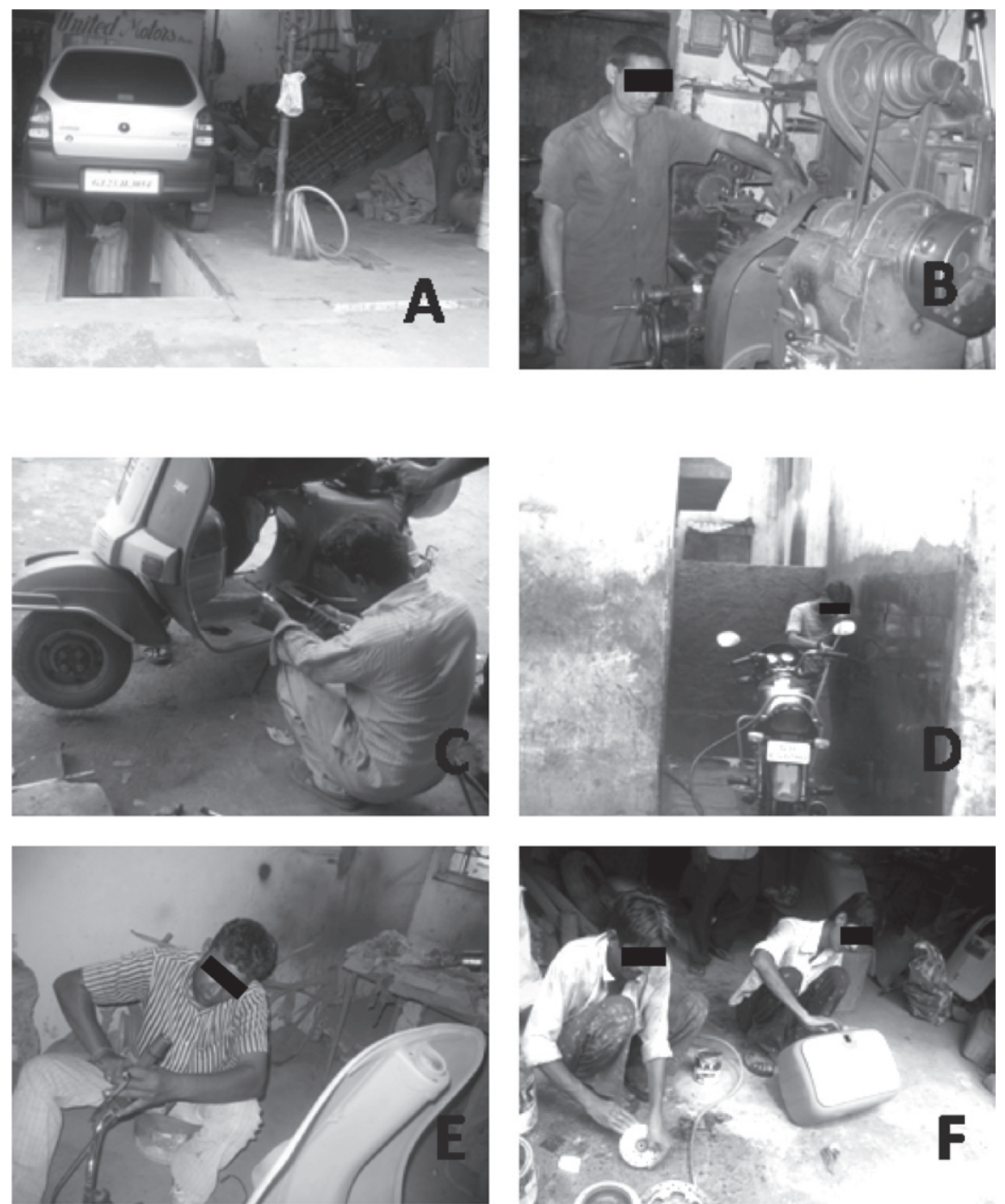

Fig. 1. Different jobs carried out at the automobile repair shops.

A. Repairing, B. Operating lathe machine, C. Welding, D. Washing, E. Repairing and F. Spray painting.

valves, bearings, breaker points or gaskets and accessories such as spark plugs; relined and adjusted brakes; soldered leaks in radiators; rebushed steering mechanism and carried out other repairs; tuned motor by adjusting the ignition, carburettor, valves and timing mechanism and finally tested the repaired vehicles in the workshop or on road. The mechanics used lathes, welding equipment and hand tools. Cleaning and washing in these units involved cleaning lint, dust, oil, and grease on automobiles. They cleaned automobiles using water hoses and pumps. They were also involved with waxing and polishing vehicles by hand.

Worker's characteristics and their association with injury occurrence

One hundred fifty three male mechanics participated in the study (Table 2). The mean age of the mechanics was $31 \mathrm{yr}$ (range 18-65). 60\% of the workers were married and $86 \%$ were literate. Nearly $47 \%$ of the workers had worked for more than $10 \mathrm{yr}$ as mechanics; the maximum duration of involvement with the occupation was $52 \mathrm{yr}$. Of the one hundred fifty three mechanics being interviewed, $34 \%$ performed repairing tasks, while $11 \%$ were involved with denting, $11 \%$ were involved with spray painting and others were involved with welding, servicing or performed automobile electrician duties. Other tasks performed by these workers were driving and cleaning. Young (OR 1.5, 95\% CI 1.1-2.3) and relatively inexperienced workers (OR 1.4, 95\% CI 1.0-1.9) were at a significantly higher risk of injury in last year. Workers who worked for more than six hours a day were at a significantly higher risk of 
Table 2. Worker characteristics and its association with injury occurrence

\begin{tabular}{lcccc}
\hline & & OR & $95 \%$ CI & $p$ value \\
\hline Age (Mean SD) years & $30.76(11.83)$ & & & \\
$\quad$ Age <20 yr (\%) & 20 & 1.5 & $1.0-2.3$ & $p<0.05$ \\
Experience (Mean SD) yr & $13.29(11.97)$ & & & \\
$\quad$ Experience (<5 yr) (\%) & 28 & 1.4 & $1-1.9$ & $p<0.05$ \\
Working hours (Mean SD) & $9.58(2.43)$ & & & \\
$\quad$ Working hours $>6 \%(\%)$ & 92 & 1.5 & $1.2-1.8$ & $p<0.05$ \\
Tobacco use & & & & \\
$\quad$ Chewing Tobacco (\%) & 46.7 & 1.4 & $0.7-2.7$ & NS \\
Smoking (\%) & 6.7 & 1.7 & $0.7-4.1$ & NS \\
Marital status & & & & \\
$\quad$ Married (\%) & 60 & 1.5 & $0.8-3.4$ & NS \\
Literacy Level & & & & \\
Literate (\%) & 86 & 0.9 & $0.3-2.5$ & NS \\
BMI (Mean SD) & $23(5.6)$ & & & \\
BMI <18 & & 0.6 & $0.3-1.3$ & NS \\
BMI 18-25 & & 1.5 & $0.7-3.4$ & NS \\
$\quad$ BMI $>25$ & & 1.3 & $0.6-2.8$ & NS \\
Task Performed by Workers (Multi tasking) & & & & \\
$\quad$ Spray Painting & 11 & & & \\
Welding & 5 & & & \\
Repairing & 34 & & & \\
Cleaning & 13 & & & \\
Driving & 16 & & & \\
Servicing & 2 & & & \\
Denting & 11 & & & \\
Electrician & 1 & & & \\
\hline
\end{tabular}

NS not significant.

injury. The study did not find association of marital status, tobacco use or literacy level with injury occurrence.

Occupational injury -types and affected body segments

In our study, $63 \%$ of the workers reported injuries at work in last year. Cuts, piercing objects, burns and bruises were chief injuries reported as shown in Fig. 2. The injured body segments reported by workers were hands $(81 \%)$, fingers $(18 \%)$, palm $(7 \%)$, legs $(6 \%)$ and head $(2 \%)$. Hands and fingers were the major regions of body being affected.

Self reported health complaints and their association with the injury

Workers reported health complaints such as respiratory problem $(16 \%)$, skin problems $(8 \%)$ and eye complaints $(20 \%)$ and data are presented in Table 3. Workers suffering from respiratory complaints (OR $4.8,95 \% \mathrm{CI} 1.4-7.3$ ) and eye related problems (OR $6.6,95 \%$ CI 2.2-20.1) were at a higher risk of injury. Workers who reported poor health status (presence of respiratory, eye related or skin related problems) were at a higher risk of injury (OR 6.8, 95\% CI 2.8-16.5).

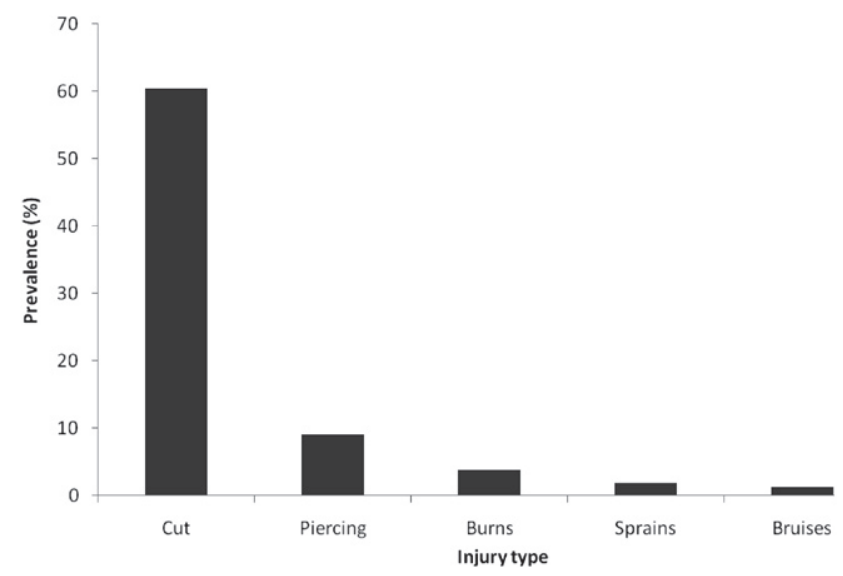

Fig. 2. Prevalence of types of injury being reported by automobile workers.

Pain and discomforts and their association with injury About $85 \%$ workers reported pain in different regions of the body during the past year. The prevalence percentage of the pain in different regions of the body is shown in Fig. 3. Upper back and lower back were the predominant regions of the body being affected. Further, workers reported high pain prevalence in shoulders and knee. $87 \%$ workers reported co-morbidity of pain in different body regions. 
Table 3. Prevalence of Stress symptoms amongst automobile repair workers and their association with pain in different body regions

\begin{tabular}{|c|c|c|c|c|c|}
\hline & \multirow{2}{*}{$\mathrm{N}$} & \multirow{2}{*}{$\begin{array}{c}\text { Prevalence } \\
(\%)\end{array}$} & \multicolumn{3}{|c|}{ Risk estimates } \\
\hline & & & OR & $95 \% \mathrm{CI}$ & $p$ value \\
\hline Chronic fatigue & 20 & 13 & 0.5 & $0.2-1.4$ & NS \\
\hline Job dis-satisfaction & 6 & 4 & 1.9 & $0.8-4.4$ & NS \\
\hline Cognitive anxiety & 34 & 23 & 0.7 & $0.3-1.7$ & NS \\
\hline Somatic anxiety & 29 & 19 & 0.8 & $0.4-2.1$ & NS \\
\hline Neuroticism & 14 & 9 & 1.2 & $0.3-4.4$ & NS \\
\hline Extroversion & 143 & 95 & 1 & $0.1-8.9$ & NS \\
\hline Cardiovascular symptoms & 5 & 3 & 2.2 & $0.2-21.3$ & NS \\
\hline Digestive symptoms & 4 & 2 & 2.8 & $0.5-14.7$ & NS \\
\hline Socio-domestic disruption & 24 & 16 & 0.9 & $0.4-2.1$ & NS \\
\hline Poor task clarity & 34 & 22 & 1.9 & $0.8-4.4$ & NS \\
\hline Poor job feedback & 19 & 32 & 3.5 & $1.5-7.5$ & $p<0.01$ \\
\hline Poor job autonomy & 31 & 20 & 1.9 & $0.8-4.7$ & NS \\
\hline Mental overload & 106 & 69 & 2.6 & $1.3-5.2$ & $p<0.001$ \\
\hline \multicolumn{6}{|l|}{ Health and well-being } \\
\hline Eye problems & 25 & 16 & 6.6 & $2.2-20.1$ & $p<0.0001$ \\
\hline Respiratory problems & 31 & 20 & 4.8 & $1.4-17.3$ & $p<0.0001$ \\
\hline Skin related problems & 12 & 8 & 1.1 & $1.0-1.1$ & NS \\
\hline \multicolumn{6}{|l|}{ Poor health } \\
\hline $\begin{array}{l}\text { (Presence of either eye, skin or } \\
\text { respiratory complaints) }\end{array}$ & 51 & 33 & 6.8 & $2.8-16.5$ & $p<0.0001$ \\
\hline
\end{tabular}

NS not significant.

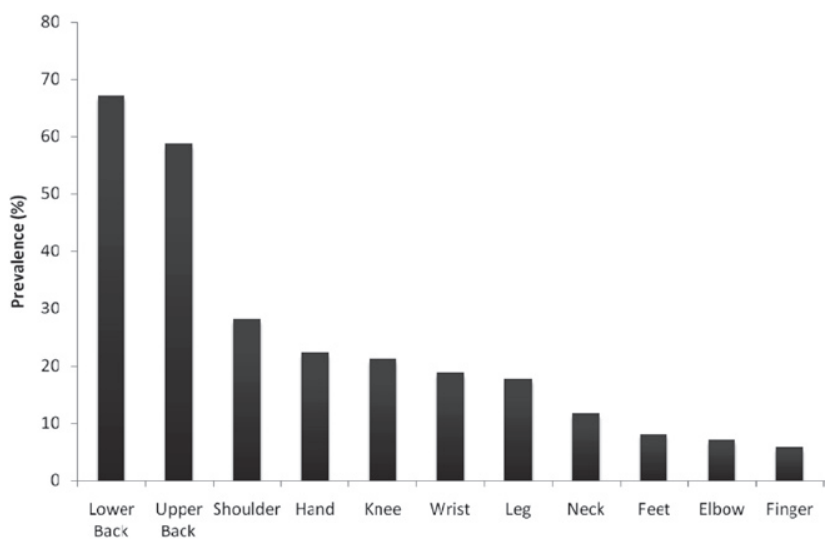

Fig. 3. Prevalence of pain and discomforts in different body regions.

Workers who reported pain in upper back (OR 3.8, 95\%CI 1.8-8.7) and lower back (OR 2.7, 95\%CI 1.3-5.7) were at a significantly higher risk of occupational injury in the same year.

Psychosocial stress symptoms and stressors and their association with injury

Prevalence of stress symptoms and their association with the injury is given in Table 3 . The study did not find associations between injury and the presence of stress symptoms such as digestive symptoms, cognitive behavioral symptoms, neurotic behavioral symptoms, somatic symptoms and socio-domestic disruptions in this workgroup. However, the stressors such as high mental overload and poor job feedback were related to injury occurrence.

\section{Work aspects and injury occurrence}

Worker's perceptions of their work aspects are given in Fig. 4. Highly specialized jobs, poor work environments (noisy, dusty and hot), high physical activity, physically demanding task situations, highly skilled jobs, poor machinery characteristics, strenuous posture and poor workplace design were perceived by the workers to be strenuous work aspects.

Relative risk estimates of work aspects with injuries is given in Table 4. Poor work environment characteristics such as hot environment (OR 2.6, 95\%CI 1-1.2), noise (OR 2.6, 95\%CI 1-6.9) and vibrations (OR 3.2, 95\% CI 1.0-9.8) were associated with injury occurrence. Task associated work activities such as high manual material handling (OR 2.7, 95\%CI 1.1-6.9), physically demanding task situations (OR 2, 95\% CI 1.4-5.2) and postural stress (OR 2, 95\% CI 1.1-5.9) were associated with occurrence of injury. Machinery characteristics (OR 2, 95\% CI 1.1-5.9), machinery control (OR 2.5, 95\% CI 1.2-5.2) and improperly designed tools (OR 4.7, 95\% CI 


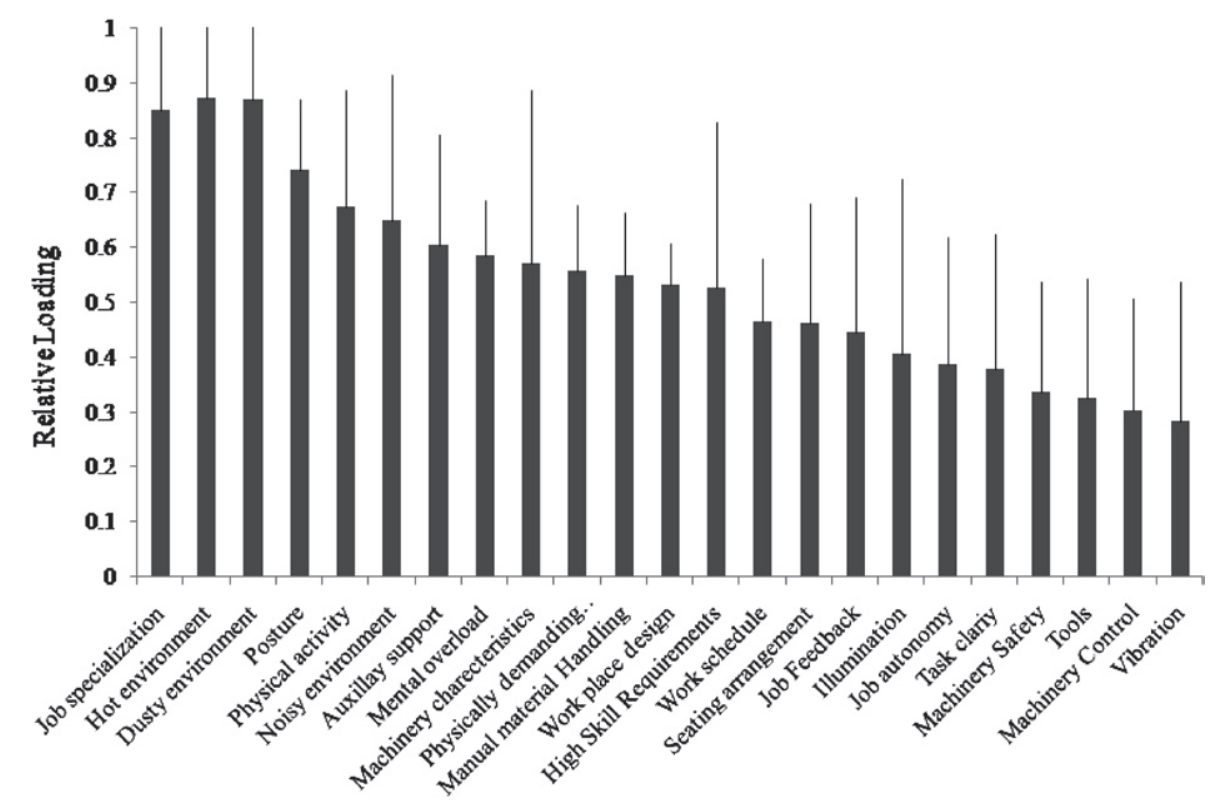

Fig. 4. Descriptive values of work aspects.

Table 4. Uni-variate analysis of association of work stressors with injury

\begin{tabular}{lccc}
\hline Work stressors & OR & CI & $p$ \\
\hline Job specialization & 1.3 & $0.7-2.5$ & 0.25 \\
Skill acquisitions & 0.9 & $0.5-1.6$ & 0.4 \\
Physical activity & 1.6 & $0.8-3.1$ & 0.1 \\
Manual material handling & 2.7 & $1.1-6.9$ & 0.04 \\
Physically demanding task situation & 2.7 & $1.4-5.2$ & 0.003 \\
Absence of auxiliary support & 4.1 & $0.7-22.1$ & 0.08 \\
Postural stress & 2.7 & $1.2-6.2$ & 0.012 \\
Noise & 2.6 & $1-6.9$ & 0.05 \\
Hot environment & 2.1 & $1-1.2$ & 0.01 \\
Poorly illuminated work places & 2.0 & $0.8-4.9$ & 0.07 \\
Dusty work environment & 4.6 & $0.8-24.9$ & 0.08 \\
Vibrations & 3.2 & $1.0-9.8$ & 0.03 \\
Poorly designed tools & 4.7 & $1.5-14.5$ & 0.0001 \\
Unsafe machinery & 1.8 & $0.7-4.3$ & 0.1 \\
Machinery control & 2.5 & $1.2-5.2$ & 0.01 \\
Machine characteristics & 2.2 & $1.1-5.1$ & 0.046 \\
Work Schedules & 2.1 & $1.4-5.6$ & 0.05 \\
\hline
\end{tabular}

NS not significant
1.5-14.5) were associated with the injury.

Multivariate analysis was done using a binary logistic regression model with a backward elimination method to understand the effect of different work stressors, psycho-social stressors and stress symptoms and worker characteristics on the injury occurrence amongst automobile repair workers as shown in Table 5. The multivariate analysis suggested that pain in upper back (OR 4.4, 95\% CI 1.5-12.1), performing highly skilled jobs (OR 2.3, 95\% CI 1.1-5.4), doing manual material handling tasks (OR 2.4, 95\%CI 1-5.5), strenuous work postures (OR 1.8, 95\%CI 1.5-22.2) noisy environment (OR 9.3, 95\% CI 1.6-9.25), vibrations in environment (OR 5, 95\%CI 1.1-22.7), poorly arranged work schedules (OR $6.9,95 \% \mathrm{CI} 1.1-6.8)$, and mismatched machinery control (OR 5.1, 95\%CI 1.4-18.1) were the factors responsible for injury occurrence in this work group.

Table 5. Results of stepwise logistic regression for disclosing the factors responsible for injury occurrence

\begin{tabular}{lccccc}
\hline \multirow{2}{*}{ Variable } & $\begin{array}{c}\text { Regression } \\
\text { Co-efficient }\end{array}$ & $\begin{array}{c}\text { Significance } \\
p \text { value }\end{array}$ & Odds Ratio & & \multicolumn{2}{c}{$95 \%$ Confidence Interval } \\
\cline { 5 - 6 } & 1.47 & 0.007 & 4.4 & 1.5 & 12.1 \\
\hline Pain in upper back & 0.8 & 0.05 & 2.3 & 1.1 & 5.4 \\
Highly skilled jobs & 0.85 & 0.05 & 2.4 & 1.0 & 5.5 \\
Manual material handling & 1.8 & 0.01 & 5.8 & 1.5 & 22.2 \\
Strenuous posture & 1.4 & 0.004 & 9.3 & 1.6 & 9.25 \\
Noise in the environment & 1.6 & 0.037 & 5 & 1.1 & 22.7 \\
Vibrations & 1.2 & 0.02 & 6.8 & 1.3 & 6.5 \\
Work schedule & 1.6 & 0.01 & 5.1 & 1.4 & 18.1 \\
Machinery control characteristics & & &
\end{tabular}




\section{Discussion}

Automobile repair work has been reported as one of hazardous occupation with high injury prevalence. Automobile repair workers are exposed to varied work related exposures such as presence of solvents and dust, strenuous work, improper work posture and improperly designed seats, long working hours and load lifting which could directly or indirectly increase workers risk of occupational injuries. With the premise that injury prevention requires analyzing frequency, severity, causes and near miss incidents which can lead to it ${ }^{1)}$, the current study attempted to identify the factors which could lead to injuries and thereby draws attention to areas which must be addressed for injury prevention.

In our study $63 \%$ of the automobile repair workers reported injuries. Workers reported higher prevalence of injuries to hands and upper extremities. Jones et al. ${ }^{28)}$ and Aggazzotti et al. ${ }^{29)}$ also reported higher prevalence of injuries in upper extremities in saw mill industry and young Italian workers respectively. We observed a high rate of cuts, burns and bruises contrary to reports of American Day laborers which suffered from injuries such as falls, burns, lacerations and crush ${ }^{26)}$. Our study indicates that upper extremity of the body requires special personal protective equipment and workers must be appropriately given training in relation to the same.

In our study, young and inexperienced workers were at a higher risk of injury. Younger inexperienced workers might be short of job related knowledge and knowhow which possibly increased their risk of injury. In our study, workers who had worked for elongated hours were at a higher risk in comparison to others who worked for shorter durations. Workers who worked for long hours might have developed fatigue, stress and drowsiness which increased their risk to injury ${ }^{30)}$. Our study did not find any association of marital status, tobacco use habits and literacy level with injury occurrence in automobile repair workers.

Our study showed that mechanics who suffered from respiratory diseases, musculoskeletal discomforts, headaches and eye complaints had an increased injury risk. Poor health of workers possibly imposed a psychological distress and had a negative effect on human performance leading to accidents causing injury occurrence. Automobile repair workplaces exposed mechanics to different hazards and absence of protective guards further increased workers risk to health and safety. Similar findings have been reported in Bristol health study which examined transient risk factors to injury occurrence ${ }^{33)}$. We suggest that health education programs and measures directed towards prevention for occupational diseases will help to improve their health and thereby successively will reduce injury occurrence.

In our study the workers who received poor job feedback and had high mental overload were at an increased risk to injury. Psychological stress symptoms and psychological stressors have been known as factors causing injury ${ }^{31-33)}$. The characteristics of automobile repair workshops which belong to the Indian unorganized sector were being congested, having restricted work area, poor illumination, high noise levels (80-90 dB) as workplaces are situated on road- sides and extreme environmental conditions - high temperatures and humidity ${ }^{34)}$. Automobile repair workers were exposed to poor work environment characterized by heat and noise which increased their risk to occupational injuries. Noisy environments might induce work related injuries by causing communication barriers, attention and concentration problems, memory impairments, stress and extreme fatigue ${ }^{35}$ ). Hot environments gave rise to cognitive decrements that resulted in unsafe behaviors at work and thereby increased occupational injury risk $^{36)}$. Although workers reported unsafe machinery and poor machinery control as risk factors but they did not got significantly predict any injury risk in our study. Machinery at times malfunctioned, jammed, or got stuck and work materials (e.g., metal stock) that were malformed or had unusual sharp edges increased mechanics risk of injury ${ }^{37)}$. Improperly designed tools were associated with injury ${ }^{38,39)}$. Strenuous postures, physically demanding task situations and manual material handling jobs possibly lead to pain, muscular tiredness and fatigue amongst automobile repair workers and increased their risk of occupational injury, which is similar to findings reported by of Bhataharjee et al. ${ }^{43)}$ in coal miners. Poor work schedules may have increased error rates by mechanics and thereby the risk of occupational injuries ${ }^{45}$. The study observes that automobile repair workers are subjected to a multitude of harsh working conditions, which imposed an injury risk on to them.

The varied factors responsible for injury occurrence were identified by regression in this workgroup and these factors have been reported to predict injury in other occupations. Pain in upper back was found to be one of the factors associated with injury risk which is similar to findings of Bhatacharjee et al. ${ }^{13)}$ in an employed population. Poor work environment characterized by high ambient noise levels and vibrations in the environment leads to increased job stress and occupational injury ${ }^{42)}$. The predictive factors identified for injuries in present automobile repair units such as moving parts of machinery, work overexertion (e.g., materials handling), poor health status, pain and discomforts in upper back and lower back, environmental stresses 
including noise, dust and heat, improperly guarded machinery have been instanced by researchers ${ }^{41,42)}$ in other occupations.

The current findings should cautiously be generalized because circumstances may differ by region and by employer. The limitation of our study was that injury occurrence was obtained by self-report rather than by medical or administrative records. Data were not available to validate it with doctor visits. On the other hand, self-reports can be a more reliable source for determining the frequency of work-related injury. With all self-reported data, the potential exists for recall bias. Some mechanics may have forgotten or outright denied they had experienced injury in the past 12 months.

\section{Conclusion}

Our study provides detailed epidemiological data on work related injuries to automobile repair workers. There was a high prevalence of occupational injury amongst male mechanics and the hand was the major body region being affected. The relative risk of occupational injury was increased amongst the mechanics that worked for elongated hours, were young, had a relatively less job experience and suffered from pain and ill-health symptoms. Poor work environment and psycho-social aspects of work increased the workers risk of injury. The study concludes that in this workgroup where no personal protective equipment and guards were in use, a reasonable and effective intervention to prevent many of these injuries would be introduction of personal protective equipment in combination with effective worker safety training.

\section{References}

1) Hunt J, Cathy C, Michael P, Anthony M (2000) Occupation-related burn injuries. J Burn Care Rehabil 21, 358-90.

2) International Labour Organization (2000) International Data Sheet on Occupation, Automobile Mechanics. ILO, Geneva.

3) Rongo L, Barten F, Msamanga G, Heederik D, Dolmans W (2004) Occupational exposure and health problems in small-scale industry workers in Dar es Salaam, Tanzania: a situation analysis. Occup Med 54, 42-6.

4) Valuri J, Routley V (1994) Injury Surveillance and Prevention in the Latrobe Valley, Hazard Special Edition.

5) Leung R, Ng Z (1978) A Preliminary look into the causative factors of occupational hand injuries in Hong Kong, preliminary look into the causative factors of occupational hand injuries in Hong Kong. Bulletin of
Hong Kong Medical Association, 37-50.

6) Mackie J (2008) Effective health surveillance for occupational asthma in motor vehicle repair. Occup Med 58, 551-5.

7) Muttamara S, Alwis K (1994) Health impacts of garage workers: a preliminary study. J Environ Health 56, 19-24.

8) Kant I, Notermans J, Borm P (1990) Observations of working postures in garages using the Ovako Working Posture Analyzing System (OVVAS) and consequent workload reduction recommendations. Ergonomics 33, 209-20.

9) Torp S, Riise P, Moen B (2001) The impact of psychosocial work factors on musculoskeletal pain: a prospective study. J Occup Environ Med 43, 120-6.

10) Chattopadhyay, $\mathrm{O}$ (2007) Pulmonary function in automobile repair workers. Indian J Community Med 32, $40-2$.

11) Santana V, Loomis D (2002) Informal jobs and nonfatal occupational injuries. Ann Occup Hyg 48, 147-57.

12) Benavides F, Benach J, Diez-Roux A, Roman C (2000) Survey on working conditions indicators? Findings from the second European how do types of employment relate to health. J Epidemiol Community Health 54, 494-501.

13) Bhattacherjee A, Chau N, Sierra O, Legras B, Benmghar L, Jean-Pierre Michely J, Ghosh A, Guillemin F, Ravaud J, Mur J, Lorhandicap Group (2003) Relationships of job and some individual characteristics to occupational injuries in employed people: a community-based study. J Occup Health 45, 382-91.

14) Zwerling C, Spnnce N, Wallace R, Davis C, Whitten P, Heeringa S (1996) Risk factors for occupational injuries among older workers: an analysis of the health and retirement study. Am J Public Health 86, 1306-9.

15) Dembe A, Erickson J, Delbos R, Banks S (2005) The impact of overtime and long work hours on occupational injuries and illnesses: new evidence from the United States. Occup Environ Med 62, 588-97.

16) Sorock G, Lombardi D, Hauser R, Eisen E, Herrick R, Mittleman M (2004) Case-crossover study of transient risk factors for transitional acute hand injury. Occup Environ Med 61, 305-11.

17) Chau N, Bourgkard E, Bhattacherjee A, Ravaud F, Choquet M, Mur M, The Lorhandicap Group (2008) Associations of job, living conditions and lifestyle with occupational injury in working population: a population-based study. Int Arch Occup Environ Health 81, 379-89.

18) Cohen A, Gjessing C, Fine L, Bernard B, McGlothlin J (1997) Elements of ergonomics program-A primer based on workplace evaluation of musculo-skeletal disorders. DHHS (NIOSH) Publ. No. 97-117.

19) Goldberg DP (1972) The Detection of Psychiatric Illness by Questionnaire. Oxford University Press, Oxford. 
20) Schwartz G, Davidson J, Goleman J (1978) Patterning of cognitive and somatic processes in the self-regulation of anxiety: effects of meditation versus exercise. Psychosomatic Med 40, 321-8.

21) Folkard S, Monk H, Lewis K, Whelpton P (1982) Individual differences and adjustments to shift work. The European Foundation for the Improvement of Living and Working Conditions, Dublin.

22) Eysenck G, Eysenck J (1964) An improved short questionnaire for the measurement of extroversion and neuroticism. Life Sci 3, 1103-9.

23) Smith S, Reilly C, Midkiff K (1989) Evaluation of three circadian rhythm questionnaires with suggestions for an improved measure of morningness. J Appl Psychol 74, 728-38.

24) Nag P (1998) Work systems-checklists. In: ILO Encyclopedia of Occupational Health and Safety, 4th Ed., 29.14-29.24 (Chapter 29), ILO Ergonomics, Geneva.

25) Jansen N, Kant I, Amelsvoort L, Nijhuis F, Brandt P (2003) Need for recovery from work: evaluating shortterm effects of working hours, patterns and schedules. Ergonomics 46, 664-8.

26) Walters N, Bourgois P, Loinaz M, Schillinger D (2002) Social context of work injury among day laborers in San Fransisco. J Gen Intern Med 17, 221-9.

27) Amell T, Kumar S, Rosser B (2001) Ergonomics, loss management, and occupational injury and illness surveillance. Part 1: elements of loss management and surveillance. A review. Int J Ind Ergon 28, 69-84.

28) Jones T, Kumar S (2004) Occupational injuries and illnesses in the sawmill industry of Alberta. Int $\mathrm{J}$ Ind Ergon 33, 415-27.

29) Aggazzotti G, Righi E, Parorno E, Fantuzzi G, Fabiani L, Giuliani A, Grappasonni I, Petrelli F, Ricciardi W, Torre G, Sciacca S, Angelillo I, Bonazzi C, Laviola F, Triassi M, Iorfida E, Montegrosso S, Rivosecchi P, Serra M, Adorisio E, Gramiccia A, Mura I, Castiglia P, Romano G, Poli A, Tardivo S (2006) Work-related injuries in young workers: an Italian multi-centric epidemiological survey. Ann 1st Super Sanita 42, 69-75.

30) Dembe A, Bianca B, Rachel A (2004) Predictor of injury and illness, National survey findings. J Occup Environ Hyg 1, 542-5.

31) Nakata A, Ikeda T, Takahashi M, Haratani T, Hojou M, Swanson M, Fujioka Y, Araki S (2006) The prevalence and correlates of injuries in small scale enterprises. J Occup Health 48, 366-76.
32) Simpson K, Jansen I, Craig W, Pickett W (2005) Multilevel analysis of association between socio-economic status ad injuries among Canadian adolescents. J Epidemiol Community Health 59, 1072-7.

33) Gangopadhyay S, Ray A, Das A, Das T, Ghoshal G, Banerjee P, Bagchi S (2003) A study on upper extremity cumulative trauma disorder in different unorganised sectors of West Bengal, India. J Occup Health 45, $351-7$.

34) Cordeiro R (2002) Suggestion of an inverse relationship between perception of occupational risks and work-related injuries. Cad Saúde Pública, Rio de Janeiro 18, 45-54.

35) Fogleman M, Akhrzadeh L, Bernard T (2005) The relationship between outdoor thermal conditions and acute injury in an aluminum smelter. Int $\mathrm{J}$ Ind Ergon 35, 47-55.

36) Lombardi D, Sorock G, Holander L, Mittleman M (2007) A case-crossover study of transient risk factors for occupational hand trauma by gender. J Occup Environ Hyg 41, 790-7.

37) Michelo P, Bra M, Moen B (2009) Occupational injuries and fatalities in copper mining in Zambia. Occu Med 59, 191-4.

38) Mital A, Pennathur A, Kansal A (1998) Nonfatal occupational injuries in the United States Part III injuries to the upper extremities. Int J Ind Ergon 25, 151-69.

39) Goldenhar L, Williams L, Swanson N (2003) Modelling relationships between job stressors and injury and near-miss outcomes for construction laborers. Work Stress 17, 218-40.

40) Leamon TB (1994) Ergonomic losses in the workplace: their reality. In: Advances in Industrial Ergonomics and Safety VI, 81-88, Aghazadeh F (Ed.), Taylor \& Francis, London.

41) Saha, A Kumar, S Vasudevan D (2008) Factors of occupational injury: a survey in a chemical company. Ind Health 46, 152-7.

42) Bhattacherjee A, Bertrand J, Meyer J, Benamghar L, OteroSierra C, Michaely J, Ghosh A, Dhoutaud A, Mur J, Chau N, Lorhandicap Group (2007) Relationships of physical job tasks and living conditions with occupational injuries in coal miners. Ind Health 45, 352-8.

43) Caruso C, Waters T (2008) A review of work schedule issues and musculo-skeletall disorders with an emphasis on health care sector. Ind Health 46, 523-34. 